\title{
A Qualitative Methodology for Studying Parent-Child Argumentation
}

4 This chapter provides a detailed exposé of the research methodology on

5 which the investigation of parent-child argumentation during meal6 time is based. In the first part, the conceptual tools adopted for the 7 analysis of argumentative discussions between parents and children, 8 i.e., the pragma-dialectical ideal model of a critical discussion and the 9 Argumentum Model of Topics, are presented. Subsequently, the process

\subsection{Conceptual Tools for the Analysis of Parent-Child Argumentation}

16 The conceptual tools adopted for the analysis of the argumentative discus- $\mathbf{A Q 1}$

17 sions between parents and children are the pragma-dialectical ideal model 18 of a critical discussion (van Eemeren \& Grootendorst, 2004), integrated 19 with the Argumentum Model of Topics (Rigotti \& Greco Morasso, 2019). 
In what follows, these conceptual tools will be described analytically. Although some elucidations have already emerged throughout the previous chapter, the nature of argumentation will now be comprehensively delineated.

\subsubsection{The Pragma-Dialectical Ideal Model of a Critical Discussion and the Reconstruction of the Argumentative Discussions}

The pragma-dialectical approach proposes the model of a critical discussion as an ideal model of argumentation developing according to the standard of reasonableness. This model describes how argumentative $\mathbf{A 2 2}$ discourse would be structured were such discourse to be solely aimed at resolving differences of opinion (van Eemeren \& Grootendorst, 2004, p. 30). This model does not describe reality, but how argumentative discourse would be structured were such discourse to be solely aimed at resolving differences of opinion (van Eemeren \& Grootendorst, 1992, p. 35). The model of a critical discussion spells out four stages that are necessary for a dialectical resolution of differences of opinion, i.e., the resolution of a dispute by means of critically testing the standpoints at issue. The first step is the confrontation stage, in which it becomes clear that there is a standpoint that is not accepted because it runs up against doubt or contradiction. In the opening stage, the parties try to find out how much relevant common ground they share as to the discussion format, background knowledge, values, to be able to determine whether their zone of agreement is sufficiently broad to conduct a fruitful discussion. In the proper argumentation stage of critical discussion, arguments in support of the standpoint(s) are advanced and critically tested. Finally, the concluding stage is the stage of a critical discussion in which the parties establish the result of an attempt to resolve a difference of opinion.

The ideal model of a critical discussion is assumed as a grid for the analysis, since it provides the criteria for the reconstruction of the argumentative discussions between parents and children. The analysis of parent-child discussions is limited to and focused on the study of analytically relevant argumentative moves, i.e., "those speech acts that, at 
53 least potentially, play a role in the process of resolving a difference of opinion" (van Eemeren \& Grootendorst, 2004, p. 73). The discussion, in fact, is considered as argumentative if the following two criteria are satisfied: (a) at least one standpoint put forth by a family member is questioned by one or more family members, and (b) at least one family member puts forward at least one argument either in favor of or against the standpoint being questioned. The findings of the analysis result in an analytic overview, which provides a reconstruction of the various components of an argumentative discussion. In an analytic overview, "all ingredients of the discourse relevant to resolving a difference of opinion on the merits are thus identified and described in terms of well-defined analytical categories" (van Eemeren, 2011, pp. 142-143). For the reconstruction of an argumentative discussion, the following components must be identified: the difference of opinion in the confrontation stage, the premises agreed upon in the opening stage, the arguments and criticisms advanced, implicitly or explicitly, during the argumentation stage, and the outcome of the discussion achieved in the concluding stage. The following example illustrates how the ideal model of a critical discussion is adopted to reconstruct in argumentative terms the discussion between a mother and her 7-year-old child, Paolo:

\section{Excerpt 2.1}

Swiss family II. Dinner 2. Family members: father (DAD, 38 years), mother (MOM, 36 years), Paolo (PAO, 7 years), Laura (LAU, 4 years and 5 months), and Elisa (ELI, 3 years and 2 months). All family members are seated at the table. DAD sits at the head of the table, MOM and PAO sit on the left-hand side of DAD, while LAU and ELI sit on their opposite side.

\%act: PAO indica alla mamma di voler prendere una gomma per cancellare il disegno e MOM fa cenno di no agitando l'indice della mano PAO indicates to his MOM he wants to take a rubber to erase a drawing and MOM says 'no' clearly by shaking her finger

$1 \quad$ *MOM: no Paolo no Paolo 


\section{A. Bova}

2 *PAO: si:

3 *MOM: quella gomma è per la lavagnetta, that rubber is for the drawing board,

$\rightarrow \quad$ *MOM: e non si usa su altre cose

4 *PAO: $\quad$ no::: and you cannot use it on other things

\section{no:::}

5 *MOM: no: tesoro, fidati. che so quello che ti dico no: sweetheart, trust me. because I know what I am talking about

$\rightarrow \quad$ *MOM: qualche volta, puoi provare sometimes, you can try

$\rightarrow \quad$ *MOM: $\quad$ altre volte non si prova, ci si fida di quello che dicono i genitori other times you cannot try, you must always trust what your parents tell you

6 *PAO: no:: non è vero! no:: it is not true!

\%act: $\quad$ PAO si alza da tavola e corre a prendere la gomma per cancellare

PAO gets up from the table and runs to take the rubber to erase

In this dialogue, there is a difference of opinion between the mother and her son, Paolo. The sequence starts when Paolo indicates to his mother that he wants to take a rubber to erase a drawing on a paper sheet. In line 1, the mother disagrees with Paolo ("no Paolo"). In line 2, the child does not put forth any argument in support of his standpoint, but he just shows his disagreement with his mother ("yes:::"). This phase of the discussion corresponds to the confrontation stage, as there is the child's standpoint (I want to use the rubber to erase) that meets with the mother's refusal (No, you cannot). The opening stage, in which the two parties decide to try and solve the difference of opinion and explore whether there are premises to start a discussion, is largely implicit. As observed by van Eemeren, Grootendorst, and Snoeck Henkemans (2002, p. 26): "It is quite common for little time to be spent on the opening of a discussion. Discussion rules and other starting points are often taken for granted and do not require explicit mentioning." At this point, in line 3, the mother puts forth an argument in support of her standpoint, making clear to her son the reason at the basis of her directive ("that rubber is for the drawing board and you cannot use it on other things"). In 
101 line 4, the child does not advance any argument in support of his stand102 point but just shows, again, his disagreement with his mother's directive 103 ("no:::"). In line 5, the mother advances another argument to convince 104 her child to change his opinion. The second argument advanced by the mother is no longer related to the properties of the eraser but states a general rule that the child must follow in similar situations and that can be paraphrased as follows: "Your parents have more experience than you. Therefore, you always have to trust them and accept what they say." This second argument put forth by the mother, however, is not effective in convincing her child to change his opinion. According to Paolo, in line 6 , the general rule stated by his mother is not right and, accordingly, he does not have to accept it. The sequence that goes from line 3 to line 6 represents the argumentation stage, as arguments in support of the standpoint are advanced by, at least, one of the two participants to the argumentative discussion. The concluding stage of the argumentative discussion between the mother and her child, Paolo, concerns a nonverbal act-Paolo gets up from the table and runs to take the rubber to erasewhich indicates that the child does not want to keep discussing this issue and thus does not accept the mother's standpoint.

The analytical overview of the discussion between the child, Paolo, and his mother is summarized below:

Issue

Standpoints

Can Paolo use the rubber to erase his drawing?

Arguments

(PAO) I want to try

(MOM) No, you cannot

(MOM) (a) That rubber is for the drawing board and you cannot use it on other things

(b) Trust me because I know what I am talking about [...] you must always trust what your parents tell you

\subsubsection{The Argumentum Model of Topics (AMT) and the Analysis of the Inferential Configuration of Arguments}

To analyze the reasoning behind the arguments put forward by parents and children, the analysis based on the pragma-dialectical ideal model of 


\section{4 A. Bova}

a critical discussion is integrated with the Argumentum Model of Topics (henceforth, AMT) (Rigotti \& Greco Morasso, 2019). The AMT is an instrument to systematically reconstruct the inferential configuration of arguments, i.e., to illustrate the structure of reasoning that underlies the connection between a standpoint and its supporting arguments. According to the AMT, to reconstruct the inferential configuration of an argument, it is necessary to find the implicit premises on which the argument is based. In particular, two fundamental components should be distinguished in identifying the inferential relation binding the premises to the conclusion of an argumentation: a procedural component and a material component. The procedural component is based on the semantic-ontological structure, which generates the inferential connection from which the logical form of the argument is derived. The material component integrates into the argument scheme the implicit and explicit premises bound to the contextual common ground.

The procedural component develops along three levels. The first level is the ontological relation, namely the locus, ${ }^{1}$ which is defined as "the source from which arguments are taken" (Rigotti \& Greco Morasso, 2019 , p. 210). The locus is not a physical place, but a conceptual one, a sort of mental space, from which the argument is drawn. Rigotti (2009) distinguishes three main categories of loci. ${ }^{2}$ The first one is represented by syntagmatic loci. As Rigotti puts it (2009, p. 166): "We speak of syntagmatic loci to indicate all the classes of arguments that refer to aspects that are ontologically linked to the standpoint, either directly or indirectly." Examples of syntagmatic loci are the following: locus from definition, loci from extensional implications (species and genus, whole and parts, quantifiers, proper and accident, place, time), loci from causes (locus from the formal cause, from the material cause, from final cause, from the efficient cause, and from instrumental cause), locus from implications and concomitances, and locus from correlates. The second category of loci is represented by paradigmatic loci. According to Rigotti (2009,

\footnotetext{
${ }^{1}$ As Rigotti (2008) remarks, contemporary argumentation theorist refers to the term locus through $\mathbf{A Q 3}$ the notion of argument scheme (cf. Garssen, 2001, 2002; Walton, Reed, \& Macagno, 2008).

${ }^{2}$ For a detailed description of the taxonomy of loci, see Rigotti (2009, pp. 166-168).
} 
159 pp. 166-167): "We speak of paradigmatic loci referring to classes formed 160 by arguments that are based on paradigmatic relations, both of opposi161 tion and of analogy (similarity)." Among the syntagmatic loci, the follow162 ing ones can be enumerated: locus from opposition, locus from analogy 163 (with the subcategories, of likeliness, difference, and isomorphism), locus 164 from "all the more..." and "all the less...", locus from alternatives, and locus from termination and setting up. Finally, the third category of loci is represented by complex loci, which are characterized "by being on the borderline between paradigmatic and syntagmatic loci” (Rigotti, 2009, p. 167). Included in this category are the locus from authority, locus from promising and warning, locus from conjugates, locus from derivate. The second level of the procedural component is the inferential connections called maxims. Examples of maxims are the following: "If a certain goal is to be achieved, it is reasonable to activate a causal chain allowing to reach it [...] If something was the case for a circumstance of the same functional genus as X, this may be the case X" (Rigotti \& Greco Morasso, 2010, pp. 495-499). The third level of the procedural component is a logical form, such as the modus ponens or the modus tollens, activated by the maxims. More specifically, provided that a certain ontological relation is the case, any inferential connection or maxim generated by it activates through its logical form in an argument scheme. Different maxims may activate identical or different logical forms. For example, the maxim "If the cause is the case, the effect is too" activates the logical form of modus ponens, while the maxim "If the effect does not take place, the cause does not either" activates a modus tollens.

The procedural component is not sufficient for a proper reconstruction of the inferential configuration of an argument. According to Rigotti and Greco Morasso (2010, p. 498): "argument schemes claim to account for the relation between real arguments used in real-life discussions and real standpoints they support [...] the validity of the maxim is a necessary but not sufficient condition for the soundness of an argumentative move: another level of premises must be taken into account." In the AMT, this second level of premises is represented in the material component, which includes two different classes of context-bound premises. The first level coincides with the Aristotelian notion of endoxon, i.e., general principles, values, and assumptions that typically belong to the 


\section{6

specific context, and which are accepted by the relevant public or by the opinion leaders of the relevant public. The second level of the material component is the datum, basically coinciding with punctual information and facts regarding the specific situation at hand, and broadly corresponding to the same concept as in Toulmin's model (1958). The datum is typically explicit, representing the information which is made clear in the discussion. The logical conjunction of the endoxon with the datum leads to the preliminary conclusion of the material component coinciding with the minor premise of the procedural component. This point of intersection is crucial in the perspective of the AMT because it represents the junction between the material and the procedural starting points and shows how different types of premises are combined in real argumentation. As Rigotti and Greco Morasso (2009, p. 52) maintain: "Topics guarantee the inferential consistency of the procedure, but, if the procedure is not combined with an endoxon, it remains a mere logical mechanism with no hold whatsoever on the public."

The Y-structure, so-called because its form looks like the letter Y, in Fig. 2.1, is the graphical tool adapted for representing the AMT's reconstruction. ${ }^{3}$

Represented in the Y-structure illustrated above is the analysis of the inferential configuration of an argument advanced by a mother during a discussion with her 5-year-old son, Leonardo. The analysis of the inferential configuration of this argument through the AMT will be presented in a later section (4.1.3). For now, I will only describe how the AMT is applied to reconstruct the reasoning behind an argument. In this example, the child wants to play with the lemon that is on the meal table. The mother disagrees with her son, since she needs the lemon to prepare the salad. The argument put forward by the mother is the following: "Because, Leonardo, your dad wants to eat a good salad today." Specified on the right-hand side of the diagram is the inferential principle, i.e., the maxim, on which the mother's argumentation is based: "If a means admits alternative uses, it is reasonable to reserve it for the use bringing to the most important purpose." This maxim 


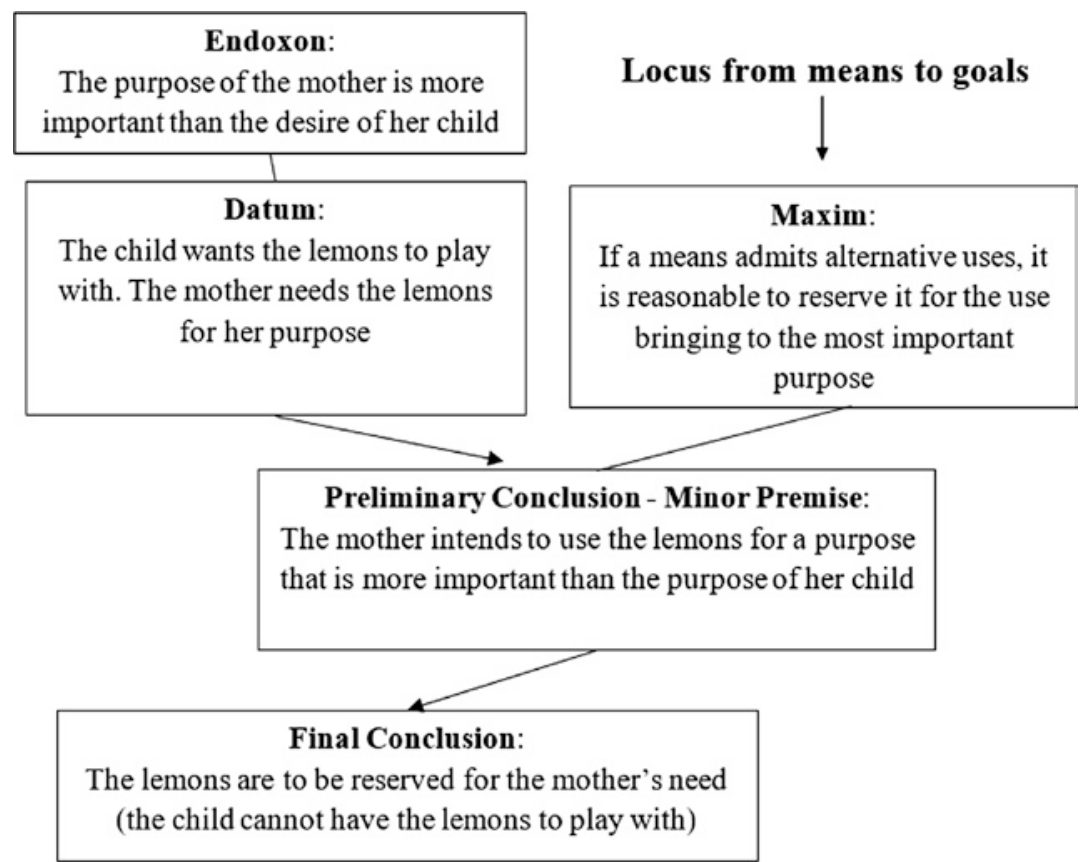

Fig. 2.1 The Y-structure representing the AMT's reconstruction of an argument advanced by a mother during a discussion with her 5-year-old son, Leonardo

228 is engendered from the locus from means to goals. For this maxim to 229 generate the final conclusion, which coincides with the standpoint to 230 be supported, the following minor premise of the topical component 231 is needed: "The mother intends to use the lemons for a purpose that is 232 more important than the purpose of her child." This leads to the final 233 conclusion that "The lemons are to be reserved for the mother's need 234 (the child cannot have the lemons to play with)." The topical component is only one part of the inferential configuration of the argument. The fact that "The mother intends to use the lemons for a purpose that is more important than the purpose of her child" needs further justification. Looking at the left-hand side of the diagram, a second line of reasoning (material component) is developed to support the former one. Unlike the maxim, this is not an inferential rule but a factual statement that must be backed by contextual knowledge. The endoxon shared by 


\section{8 A. Bova}

Leonardo and his mother concerns the common knowledge about the order of priority within the family context: "The purpose of the mother is more important than the desire of her child." The datum constituting the minor premise of the endoxical syllogism is that "The child wants the lemons to play with. The mother needs the lemons for her purpose." This leads to the preliminary conclusion of the endoxical syllogism, which coincides with the minor premise of the topical component, that "The mother intends to use the lemons for a purpose that is more important than the purpose of her child."

Despite its particular concern for the inferential aspects of argumentation, the AMT, de facto, accounts not only for the logical aspects of the development of argumentation but also for its embeddedness in the parties' relationship. Beyond the possibility of analyzing the process of reasoning underlying an argument, this aspect represents the main reason why I have chosen to use the AMT to analyze parent-child argumentative discussions.

\subsection{Corpus of Data}

The study presented in this volume takes as its empirical base a quasi-homogeneous corpus constructed from two different sets of data, named sub-corpus 1 and sub-corpus 2. Sub-corpus 1 consists of 15 video recordings and related transcriptions of mealtime conversations in five Italian families collected in the city of Rome (Italy). ${ }^{4}$ Sub-corpus 2 , created in the city of Lugano ${ }^{5}$ (Switzerland), consists of 15 video recordings and related transcriptions of mealtime conversations in five Swiss families. Despite the data corpus on which the present study is based is constituted of families of two different nationalities, a cultural

\footnotetext{
${ }^{4}$ I want to thank Clotilde Pontecorvo and her colleagues at the University of Rome "La Sapienza", Italy, for allowing that a part of the broad corpus of video-recordings of family mealtime conversations in Italian families could be used as part of the data corpus of the present study.

${ }^{5}$ Lugano is the largest city in the southernmost canton of Switzerland, the canton of Ticino. Switzerland has four national languages: French, German, Italian, and Romansh. The canton of Ticino is the only canton in Switzerland where the sole official language is Italian.
} 
comparison aimed at singling out differences and similarities between the two sub-corpora from an argumentative point of view is not a goal of this study. The criteria adopted in the selection of the Swiss families mirror the criteria adopted in the creation of sub-corpus 1: the presence of both parents and at least two children, of whom the younger is of preschool age (3-year-old to 6-year-old). All participants are Italianspeaking. Participating families did not receive any financial reimbursement for their participation in the study.

\subsubsection{Sub-corpus 1 Italian Families: Sample Characteristics}

Included in sub-corpus 1 , based on the parental answers to questionnaires about socioeconomic status (SES) and personal details of family members that participants filled before the video recordings, were five middle- to upper-middle-class Italian families, all residents of Rome. Most parents at the time of data collection were in their late 30s. Fathers were slightly older than mothers. All families in sub-corpus 1 had two children. To ensure the anonymity of participants, all names in this volume are pseudonyms. Detailed information on family constellations in sub-corpus 1 are presented in Table 2.1.

\subsubsection{Sub-corpus 2 Swiss Families: Recruitment of the Families and Sample Characteristics}

The Swiss families were selected through the snowball technique (also known as chain referral sampling) (Goodman, 1961; Heckathorn, 1997, 2002), by which the candidate families contacted helped the researchers to find others. The process of selection was carried out in the city of Lugano, and all families in this study expressed a keen interest in participating. After an initial contact by phone, the researchers visited the families in their own homes and I described to parents the research plan. The families were informed that this study aimed to investigate the style of their mealtime conversations, but nothing was said about the specific interest in argumentative discussions. As specified in a 
Table 2.1 Sub-corpus 1-Italian families

\begin{tabular}{|c|c|}
\hline Family group & Italian (sub-corpus 1) \\
\hline $\begin{array}{l}\text { Length of recordings in minutes } \\
\text { Mean length of recordings in minutes }\end{array}$ & $\begin{array}{l}20-37 \\
32.41\end{array}$ \\
\hline $\begin{array}{l}\text { Participants } \\
\text { FAM_1 } \\
\text { Mom: Ester ( } 38 \text { years) } \\
\text { Dad: Paolo ( } 38 \text { years) } \\
\text { Child 1: Silverio ( } 8 \text { years) } \\
\text { Child 2: Gabriele (5 years and } 4 \text { months) }\end{array}$ & $\begin{array}{l}\text { FAM_4 } \\
\text { Mom: Flavia ( } 34 \text { years) } \\
\text { Dad: Sergio ( } 38 \text { years) } \\
\text { Child 1: Gabriele ( } 8 \text { years and } 5 \text { months) } \\
\text { Child 2: Daniele (5 years and } 4 \text { months) }\end{array}$ \\
\hline $\begin{array}{l}\text { FAM_2 } \\
\text { Mom: Marta (33 years) } \\
\text { Dad: Gianfranco ( } 34 \text { years) } \\
\text { Child 1: Giorgia ( } 6 \text { years and } 6 \text { months) } \\
\text { Child 2: Clara (3 years and } 10 \text { months) }\end{array}$ & $\begin{array}{l}\text { FAM_5 } \\
\text { Mom: Paola ( } 40 \text { years) } \\
\text { Dad: Fabrizio ( } 42 \text { years) } \\
\text { Child 1: Marco ( } 8 \text { years and } 6 \text { months) } \\
\text { Child 2: Leonardo ( } 5 \text { years and } 7 \text { months) }\end{array}$ \\
\hline $\begin{array}{l}\text { FAM_3 } \\
\text { Mom: Sara (37 years) } \\
\text { Dad: Matteo ( } 37 \text { years) } \\
\text { Child 1: Samuele ( } 7 \text { years and } 11 \text { months) } \\
\text { Child 2: Adriana ( } 5 \text { years and } 4 \text { months) }\end{array}$ & \\
\hline $\begin{array}{l}\text { Mothers } \\
\text { Fathers } \\
\text { Adults, total }\end{array}$ & 10 \\
\hline $\begin{array}{l}\text { Sons } \\
\text { Daughters } \\
\text { Children, total }\end{array}$ & $\begin{array}{l}7 \\
3 \\
10\end{array}$ \\
\hline $\begin{array}{l}\text { Children aged from } 3 \text { to } 6 \\
\text { Older siblings }\end{array}$ & $\begin{array}{l}5 \\
5\end{array}$ \\
\hline Total participants & 20 \\
\hline
\end{tabular}

release letter signed by the researchers and the parents, all families gave us permission to tape, provided the data would be used only for scientific purposes and privacy would be guaranteed. At the end of the transcription phase, the families were given a copy of the video as a token of gratitude for their participation. Included in sub-corpus 2, based on the parental answers to questionnaires about SES and personal details of family members that participants filled before the video recordings, 
Table 2.2 Sub-corpus 2-Swiss families

\begin{tabular}{|c|c|}
\hline Family group & Italian (sub-corpus 2) \\
\hline $\begin{array}{l}\text { Length of recordings in minutes } \\
\text { Mean length of recordings in minutes }\end{array}$ & $\begin{array}{l}19-42 \\
35.12\end{array}$ \\
\hline $\begin{array}{l}\text { Participants } \\
\text { FAM_1 } \\
\text { Mom: Luisa ( } 38 \text { years) } \\
\text { Dad: Marco ( } 41 \text { years) } \\
\text { Child 1: Luca ( } 6 \text { years and } 8 \text { months) } \\
\text { Child 2: Luisa ( } 3 \text { years and } 11 \text { months) }\end{array}$ & $\begin{array}{l}\text { FAM_4 } \\
\text { Mom: Cristina ( } 34 \text { years) } \\
\text { Dad: Massimo ( } 36 \text { years) } \\
\text { Child 1: Stefano ( } 8 \text { years and } 5 \text { months) } \\
\text { Child 2: Alessandro ( } 4 \text { years and } 6 \text { months) }\end{array}$ \\
\hline $\begin{array}{l}\text { FAM_2 } \\
\text { Mom: Maria ( } 36 \text { years) } \\
\text { Dad: Giuseppe ( } 38 \text { years) } \\
\text { Child 1: Paolo (7 years) } \\
\text { Child 2: Laura ( } 4 \text { years and } 5 \text { months) } \\
\text { Child 3: Elisa (3 years and } 2 \text { months) }\end{array}$ & $\begin{array}{l}\text { FAM_5 } \\
\text { Mom: Chiara ( } 37 \text { years) } \\
\text { Dad: Andrea ( } 37 \text { years) } \\
\text { Child 1: Francesco ( } 6 \text { years and } 3 \text { months) } \\
\text { Child 2: Michele ( } 4 \text { years and } 2 \text { months) }\end{array}$ \\
\hline $\begin{array}{l}\text { FAM_3 } \\
\text { Mom: Sara ( } 34 \text { years) } \\
\text { Dad: Carlo (39 years) } \\
\text { Child 1: Manuela ( } 7 \text { years and } 4 \text { month } \\
\text { Child 2: Filippo ( } 5 \text { years and } 1 \text { month) } \\
\text { Child 3: Carlo (3 years and } 1 \text { month) }\end{array}$ & \\
\hline $\begin{array}{l}\text { Mothers } \\
\text { Fathers } \\
\text { Adults, total }\end{array}$ & $\begin{array}{l}5 \\
5\end{array}$ \\
\hline $\begin{array}{l}\text { Sons } \\
\text { Daughters } \\
\text { Children, total }\end{array}$ & $\begin{array}{l}8 \\
4 \\
12\end{array}$ \\
\hline $\begin{array}{l}\text { Children aged from } 3 \text { to } 6 \\
\text { Older siblings }\end{array}$ & $\begin{array}{l}7 \\
5\end{array}$ \\
\hline Total participants & 22 \\
\hline
\end{tabular}

were five middle- to upper-middle-class Swiss families, all residents of Lugano. At the time of data collection, most parents were in their mid30s. Fathers were slightly older than mothers. Families had two or three children. To ensure the anonymity of participants, all names in this volume are pseudonyms. Detailed information on family constellations in sub-corpus 2 is presented in Table 2.2. 


\section{A. Bova}

\subsection{Data Collection and Procedures} for the Transcription of Oral Data

To minimize researcher interference, family members were told to act as normally as possible, and the recordings were made by the families themselves. However, even though the family members were told to act as they normally do without the video camera, and despite their seeming indifference toward the video camera, the intrusion in their life routine that the participation in the study involved cannot be denied. In the following sections, we will discuss practical problems faced in collecting parent-child mealtime conversations.

The equipment was delivered to the family and the researchers demonstrated how to use the video equipment and how to assemble the tripod. Families videotaped their meals three times over a fourweek period. For videotaping, the camera was placed at an angle that showed the dining table, and the mealtime conversations were recorded in their entirety, i.e., since the family began to gather around the table and stopped when they left the table. The length of the recordings varies from 20 to 40 minutes. As regards the technical aspects, DV cameras were used as they allow storage in a durable physical form. The data were transferred to digital form with a dedicated PC and the digital copy of each interaction was reproduced twice and copied onto two DVDs which were stored in different buildings to ensure maximum durability of the data.

In a first phase, family meals were fully transcribed adopting the CHILDES standard transcription system CHAT (MacWhinney, 2000), with some modifications introduced to enhance readability, and revised by two researchers until a high level of consent (agreement rate $=90 \%$ ) has been reached. Verbal utterances and nonverbal expressions with a clear communicative function relevant to the meal activity were identified and clearly described in the transcription. This methodology allowed a detailed analysis of verbal interactions among family members during the recording sessions. Afterwards, the researchers reviewed together with the family members all the transcriptions at their home. 
345 This procedure made it possible to ask the family members to clarify passages that were unclear in the eyes of the researchers because of the low level of recording sound and vague words and constructions. Information on the physical setting of the mealtime, i.e., a description of the kitchen and of the dining table, was also made for each family meal. In the transcription of the conversations, this practice has proved very useful for understanding some passages that, at first sight, appeared unclear. The direct experience of the entire process of corpus construction, including the recording of the interaction (construction of primary data), and the transcription (construction of secondary data), has allowed both the application of the availability principle, i.e., "the analytical task of recording (and, in the same way, of digitising, anonymizing transcribing, annotating, etc.) is to provide for the availability of relevant details-which indeed makes the analysis possible" (Mondada, 2006, p. 55), and a fuller experiential understanding of the specific situations.

In all examples, all turns are numbered progressively within the discussion, and family members are identified by role (for adults) and by name (for children). Italian data are presented in the original, using Times New Roman font, whereas the English translation is added below using Times New Roman Italic font. The transcript follows CHAT in using the following conventions:

* Indicates the speaker's turn

[...] Not-transcribed segment of talking

(()) Segments added by the transcriber to clarify some elements of the situation

[ = !] Segments added by the transcriber to indicate some paralinguistic features

xxx Inaudible utterance(s)

\%act: Description of the speaker's actions

\%sit: Description of the situation/setting

Several deviations from CHAT were introduced. First, punctuation symbols, as employed by Schiffrin (1994) and Blum-Kulka (1997), were used to indicate intonation contours: 
A. Bova

Continuing intonation Falling intonation Prolonging of sounds Rising intonation Exclamatory intonation

Second, additional symbols were added:

$\rightarrow$ pau:
Maintaining the turn of talking by the speaker $2.5 \mathrm{sec}$ End of the family meal

\subsection{Ethical Issues and Practical Problems in Collecting Parent-Child Mealtime Conversations}

Collecting parent-child mealtime interactions poses several challenges because respecting the privacy of the participants is one of the most important issues in research (Berg \& Lune, 2012; Salkind, 2003; Taylor \& Bogdan, 1998). The ethical framework that guided this study included informed consent from the participants, anonymity, and confidentiality, All participants were approached by means of an information sheet outlining in clear language the general purpose of the study and providing information about how the video data would be used. Consent letters were written in accordance with Swiss Psychological Society (SPS) and American Psychological Association (APA) guidelines, specifically the format outlined in the fifth edition of the Publication Manual of the American Psychological Association (APA, 2009). As specified in a release letter signed by the researchers and the parents, families gave us permission to video-record their mealtimes, provided the data would be used only for scientific purposes and privacy would be guarded. Moreover, in line with the ethical framework guiding the research, the families were assured that their anonymity would be maintained at all stages of the study. 
Anonymity was maintained across studies by means of the use of a single master sheet which contained the name of each participant and their participant number. All names in this volume are pseudonyms. Transcriptions, video-recorded material, and information on the families were treated in the strictest confidence and seen only by researchers. Segments of video-recorded data were used for research purposes only. The package also made clear to participants that they could choose to withdraw from the study at any time and that any concerns they had about the ethics of the study could be referred to the researchers for clarification at any time.

Other challenges in collecting parent-child mealtime conversations refer to practical problems associated with recording quality and difficulty of transcription. Multiparty interactions are more difficult to transcribe than monologues and dyadic interactions. As observed by Pan, Perlmann, and Snow (2000), the time invested in transcribing $30 \mathrm{~min}$ utes of mealtime conversations can be often much longer than the time involved in transcribing a dyadic interaction of similar length. Problems facing transcribers include discriminating among family members, especially if there is more than one child; the frequent impossibility of determining who the addressees are; and situations in which children move from the meal-table or do not participate in the conversation. Other challenges have to do with ensuring that the taped mealtime is as natural as possible and with the research design adopted for the study. For example, even though the family members were told to act as they normally do, the fact of being video-recorded provoked, at times, a shift of family members' attention toward the video camera, like in the following conversation:

\section{Excerpt 2.2}

Swiss family II. Dinner 1. Family members: father (DAD, 38 years), mother (MOM, 36 years), Paolo (PAO, 7 years), Laura (LAU, 4 years and 5 months), and Elisa (ELI, 3 years and 2 months). All family members are seated at the table. DAD sits at the head of the table. MOM and PAO sit on the left-hand side of DAD, while LAU and ELI sit on their opposite side. 


\begin{tabular}{|lll|}
\hline Layout: Pop_A5 & Book ID: $\mathbf{4 7 7 5 3 8 \_ 1 \_ E n}$ & Book ISBN: 978-3-030-20457-0 \\
Chapter No.: 2 & Date: $\mathbf{1 6}$ May 2019 18:22 & Page: $36 / 38$ \\
\hline
\end{tabular}

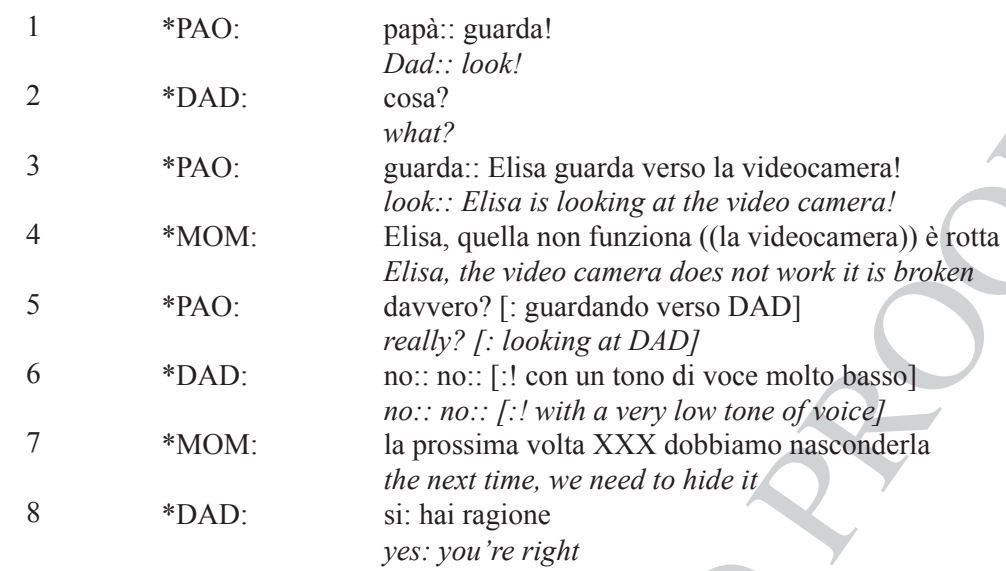

Because of their desire to give a good impression of themselves in front of the camera, parents and children during the video recording of their meals might not be inclined to behave as they normally do. This is indeed unavoidable, and the researcher has no control over it. Such a bias is present in all types of research which deal with people and respect the basic ethical principle of informed consent of participants. The only thing the researcher can do in these cases is to be aware of the problem and to consider it in the analysis and the discussion of the results. In the creation of sub-corpus 2, the video recordings were made by the families themselves because the presence of the researcher during mealtime could encourage even more the tendency of families toward social desirability than being on their own.

Further challenges derive from the advantages and disadvantages of the research design adopted for the study of mealtime conversations. On the one hand, the limited number of recordings $(N=30)$ favored a more careful analysis but did not allow certain quantifications, such as the correlation between categories. A larger database would probably permit more quantitatively reliable data for certain statistical relationships. On the other hand, careful studies of a small number of conversations in a natural setting may give rise to a more penetrating and "data-close" analysis of the argumentative dynamics among family members. Using mealtime conversations does not automatically solve 
the problem of obtaining optimal family interaction data. No data are perfect. Nevertheless, mealtime conversations are a highly informative source for the study of parent-child argumentation, and generally, they are an invaluable source for studying the dynamics of family interactions.

\section{References}

APA. (2009). Publication manual of the American Psychological Association (6th ed.). Washington, DC: American Psychological Association.

Berg, B. L., \& Lune, H. (2012). Qualitative research methods for the social sciences (8th ed.). Boston, MA: Pearson.

Bigi, S. (2012). Contextual constraints on argumentation: The case of the medical encounter. In F. H. van Eemeren \& B. Garssen (Eds.), Exploring argumentative contexts (pp. 289-303). Amsterdam: Wiley.

Blum-Kulka, S. (1997). Dinner talk: Cultural patterns of sociability and socialization in family discourse. Mahwah, NJ: Erlbaum.

Bova, A. (2015a). "This is the cheese bought by Grandpa": A study of the arguments from authority used by parents with their children during mealtimes. Journal of Argumentation in Context, 4(2), 133-157.

Bova, A. (2015b). Adult as a source of expert opinion in child's argumentation during family mealtime conversations. Journal of Argumentation in Context, 4(1), 4-20.

Garssen, B. J. (2001). Argument schemes. In F. H. van Eemeren (Ed.), Crucial concepts in argumentation theory (pp. 81-100). Amsterdam: Amsterdam University Press.

Garssen, B. J. (2002). Understanding argument schemes. In F. H. van Eemeren (Ed.), Advances in pragma-dialectics (pp. 93-104). Amsterdam: SicSat.

Goodman, L. A. (1961). Snowball sampling. Annals of Mathematical Statistics, $32(1), 148-170$.

Greco Morasso, S. (2012). Contextual frames and their argumentative implications: A case-study in media argumentation. Discourse Studies, 14(2), 197-216.

Heckathorn, D. D. (1997). Respondent-driven sampling: A new approach to the study of hidden populations. Social Problems, 44(2), 174-199.

Heckathorn, D. D. (2002). Respondent-driven sampling II: Deriving valid estimates from chain-referral samples of hidden populations. Social Problems, 49(1), 11-34. 
MacWhinney, B. (2000). The CHILDES project: Tools for analyzing talk (3rd ed.). Mahwah, NJ: Erlbaum.

Mondada, L. (2006). Video recording as the preservation of fundamental features for analysis. In H. Knoblauch, J. Raab, H. G. Soeffner, \& B. Schnettler (Eds.), Video analysis (pp. 51-68). Bern: Lang.

Pan, B. A., Perlmann, R. Y., \& Snow, C. E. (2000). Food for thought: Dinner table as a context for observing parent-child discourse. In L. Menn \& N. B. Ratner (Eds.), Methods for studying language production (pp. 205-224). Mahwah, NJ: Lawrence Erlbaum Associates.

Rigotti, E. (2009). Whether and how classical topics can be revived within contemporary argumentation theory. In F. H. van Eemeren \& B. Garssen (Eds.), Pondering on problems of argumentation (pp. 157-178). Dordrecht: Springer.

Rigotti, E., \& Greco Morasso, S. (2009). Argumentation as an object of interest and as a social and cultural resource. In N. Muller-Mirza \& A. N. Perret-Clermont (Eds.), Argumentation and education (pp. 1-61). New York, NY: Springer.

Rigotti, E., \& Greco Morasso, S. (2010). Comparing the argumentum model of topics to other contemporary approaches to argument schemes: The procedural and material components. Argumentation, 24(4), 489-512.

Rigotti, E., \& Greco Morasso, S. (2019). Inference in argumentation: A topics-based approach to argument schemes. Cham: Springer.

Salkind, N. J. (2003). Exploring research (5th ed.). Upper Saddle River, NJ: Prentice Hall.

Schiffrin, D. (1994). Approaches to discourse. Cambridge, MA: Blackwell.

Taylor, S. J., \& Bogdan, R. (1998). Introduction to qualitative research methods (3rd ed.). New York, NY: Wiley.

Toulmin, S. E. (1958). The uses of argument. Cambridge: Cambridge University Press.

van Eemeren, F. H. (2011). In context: Giving contextualization its rightful place in the study of argumentation. Argumentation, 25(2), 141-161. van Eemeren, F. H., \& Grootendorst, R. (1992). Argumentation, communication, and fallacies: A pragma-dialectical perspective. Hillsdale, NJ: Erlbaum. van Eemeren, F. H., \& Grootendorst, R. (2004). A systematic theory of argumentation: The pragma-dialectical approach. Cambridge: Cambridge University Press. van Eemeren, F. H., Grootendorst, R., \& Snoeck Henkemans, A. F. (2002). Argumentation: Analysis, evaluation, presentation. Mahwah, NJ: Lawrence Erlbaum Associates.

Walton, D. N., Reed, C., \& Macagno, F. (2008). Argumentation schemes. Cambridge: Cambridge University Press. 


\begin{tabular}{|l|}
\hline \multicolumn{2}{|c|}{ Author Query Form } \\
\hline Book ID: 477538_1_En \\
Chapter No: 2 \\
\hline Please ensure you fill out your response to the queries raised \\
below and return this form along with your corrections. \\
Dear Author, \\
During the process of typesetting your chapter, the following queries have \\
arisen. Please check your typeset proof carefully against the queries listed \\
below and mark the necessary changes either directly on the proof/online \\
grid or in the 'Author's response' area provided
\end{tabular}

\begin{tabular}{|c|c|c|}
\hline Query Refs. & Details Required & Author's Response \\
\hline AQ1 & $\begin{array}{l}\text { Please check and confirm the edit made in the chapter title and } \\
\text { running heads. }\end{array}$ & \\
\hline $\mathrm{AQ} 2$ & $\begin{array}{l}\text { Kindly suggest whether the sentence 'This model describes ... } \\
\text { of opinion' can be deleted since the following sentence conveys } \\
\text { the same meaning. }\end{array}$ & \\
\hline AQ3 & $\begin{array}{l}\text { Reference 'Rigotti (2008)' is cited in the text but not provided } \\
\text { in the reference list. Please provide the respective reference in } \\
\text { the list or delete this citation. }\end{array}$ & \\
\hline AQ4 & $\begin{array}{l}\text { Reference 'Bova and Arcidiacono (2013)' is cited in the text } \\
\text { but not provided in the reference list. Please provide the } \\
\text { respective reference in the list or delete this citation. }\end{array}$ & \\
\hline
\end{tabular}

